\title{
Long-term outcome of atrial septal defect (ASD) repair by the figulla flex II ASD occluder:A retrospective cohort study at a referral heart center in Iran
}

\begin{abstract}
Background: By developing the third generation of occluders such as the Figulla Flex II ASD occluder for Atrial Septal Defect (ASD) repairing, the risk of post-procedural adverse events has been significantly reduced. We evaluated the long-term results of ASD device closure using the Figulla Flex II ASD occluder in a tertiary heart center in Iran to assess the brief consequences of the device and procedure.
\end{abstract}

Methods: Three hundred and sixty-five patients undergoing Figulla Flex II ASD occluder insertion for ASD repair at Shahid Rajaee Cardiovascular Medical and Research Center in Tehran reviewed retrospectively. The patients were followed for a mean time of $31.7 \mathrm{months}$ (ranged 12 to 51 months) to assess the long-term outcome and the patients' complicationfree survival.

Results: The most common post-procedure complications within the follow-up time included cardiac arrhythmia [Premature Ventricular Contraction (PVC) in 18 patients and Paroxysmal Supraventricular Tachycardia (PSVT) in 5 patients], erosion in 2 patients and clot on device in 2 patients. The patients' functional status significantly improved after ASD device closure. The overall Major Adverse Cardiac Event (MACE) rate was indicated to be $4.9 \%$. Among baseline variables, the size of ASD and the size of the device could effectively predict the likelihood of long-term MACE. According to the survival analysis, 1,2 , and 3-year free-MACE survival rates were $99.7 \%, 99.1 \%$, and $90.6 \%$, respectively.

Conclusion: ASD repair by the Figulla Flex II ASD occluder leads to a favorable long-term outcome with a three-year free MACE survival rate of more than $90 \%$. This proper outcome may be adversely affected by a large ASD size.

Keywords: atrial septal defect, figulla flex II ASD occlude, complications of percutaneous closure
Volume I 3 Issue I - 2020

\author{
Ata Firouzi,' Aisha Siraj, ${ }^{2 *}$ Amir Masoud \\ Jafari,'Hamid Reza Sanati,' Zahra Khajail, ${ }^{3}$ \\ Ali Zahedmehr,' Feridoun Noohi,' Seddighe \\ Saeidi, ${ }^{3}$ Hossein Ali Basiri,' Mahmoud \\ Momtahen,' Ahmad Mohebbi,' Farshad \\ Shakerian,' Bahram Mohebbi,' Mohsen \\ Madani,' 'Majid Kiavar,' Reza Kiani,' Negar \\ Salehi ${ }^{4}$ \\ 'Fellowship of Interventional Cardiology, Cardiovascular \\ Intervention research Center, Rajaie Cardiovascular Medical and \\ Research Center, Iran University of Medical Sciences, Tehran, \\ Iran \\ ${ }^{2}$ Interventional Cardiologist, Assistant professor at Case \\ Western Reserve University, MetroHealth Medical Center, \\ Cleveland, Ohio, USA \\ ${ }^{3}$ Fellowship of adult congenital Heart Diseases, Cardiovascular \\ Intervention Research center, Rajaie Cardiovascular Medical and \\ Research Center, Iran University of Medical Sciences, Tehran, \\ Iran \\ ${ }^{4}$ General Cardiology Fellow, University of Arkansas for Medical \\ Sciences, Little Rock, Arkansas,USA
}

\begin{abstract}
Correspondence: Aisha Siraj, Interventional Cardiologist, Assistant professor at Case Western Reserve University, MetroHealth Medical Center, Cleveland, Ohio, USA, Tel + I 718675927I,Email Aishasiraj@gmail.com
\end{abstract}

Received: January 21, 2020 | Published: February 12, 2020

\begin{abstract}
Abbreviations: ASD, atrial septal defect; PVC, premature ventricular contraction; PSVT, paroxysmal supraventricular tachycardia; MACE, major adverse cardiac event; CHDs, congenital heart diseases; ASO, amplatzer septal occluder; SD, standard deviation
\end{abstract}

\section{Introduction}

Atrial Septal Defect (ASD) is now identified as the most frequent congenital heart diseases (CHDs). ${ }^{1}$ Due to its asymptomatic nature, it is also the most common important CHDs finding in adults. ${ }^{2}$ As there were significant mortality and morbidity related to ASD and its associated repair procedures, the therapeutic strategy of ASD repair has been modified over the last decades. In this regard and to minimize disease-related adverse events, various techniques and devices, particularly minimal invasive types, such as trans-catheter procedures, have been developed to close the defect appropriately. These changes lead to an excellent post-procedural outcome as compared to invasive surgeries. ${ }^{3,4}$ The efficacy and safety of each selected procedure may be dependent on several baseline factors such as patient's selection, preprocedural characteristics like size, number of defects and potential cardiovascular risk profile, peri-procedural assessments along with the type of techniques. In other words, preoperative hemodynamic stability, morphologic features of the defect, and the quality of the equipment that will be used, such as type and size of the device, can all affect the outcome of repairing procedure at any age.$^{5-7}$ In addition to baseline risk, the safety of the methods of the procedure base on procedural principles, characteristic features of available devices are essential to be determined. ${ }^{8}$

The Amplatzer Septal Occluder (ASO) is now one of the most widely used devices for trans-catheter closure of ASD. Although the ASO resolved some potential limitations of previous methods such as the non-negligible rate of residual shunt and frame fracture, it may still lead to severe cardiac adverse events in about $0.2 \%$ of patients mainly due to oversizing the device due to the size of the defect and aortic rim deficiency. ${ }^{9}$ ASD sizing is usually based on the TEE that will evaluate the size and rims. Although before closure in the catheterization lab, the uses of the sizing balloon will help and, based on the waste will measure the ASD size and estimate the appropriate device size (Figures 2). The initial study revealed a failure rate of $4.3 \%$ with significant and total adverse effects of $1.6 \%$ and $7.2 \%$, respectively. ${ }^{10}$ By developing the third generation of occluders like the Figulla Flex II ASD occluder, the risk for cardiac erosion has been significantly reduced. Some large studies demonstrated high efficacy 
with low complication rate $(<1 \%)$ when Figulla Flex II ASD occluder is used..$^{10}$ However, in some other studies, comparable efficacy and safety were shown compared to ASO. ${ }^{11,12}$ Because of the contradictory results regarding the consequences of the use of Figulla Flex II ASD occluder as a new generation of ASD repair technique, we evaluated the long-term efficacy of using this device in a tertiary referral heart center to find a more unobstructed view of the values about this new device.

\section{Materials and methods}

Shahid Rajaee Cardiovascular, Medical, and Research Center in Tehran, Iran, are a large tertiary center for CHDs, with about 100 admissions annually. The baseline, procedural, and even early and long-term outcomes of repairing procedures were consecutively collected and gathered as a large prospective data registry with the aim of retrospective and prospective assessment of the proceduralrelated result. From 2015 to 2019, 365 ASD repairing procedures were performed using the Figulla Flex II ASD occluder in this center. By reviewing the data recorded in the pointed data registry, preoperative characteristics including the patients' demographics, right ventricular size, baseline clinical manifestations (dyspnea, palpitation or chest pain), lesion-related parameters (number and size of defects and characteristics of rims), peri-procedural events such as cardiac arrhythmia, cardiac arrest, device malposition, air embolism, tamponade, transfer to open surgery, femoral site complications, as well as in-hospital post-procedural complications such as erosion, occurrence of clot, arrhythmias, sudden cardiac death, deterioration of clinical symptoms and also prolonged hospital stay were assessed. Long-term follow-up of repairing procedures was performed by the telephone encounters and reviewing the hospital records. The study endpoint was to evaluate the prevalence of early and long-term adverse cardiac events and risk factors for the poor procedural outcome.

For statistical analysis, the results were presented as mean \pm standard deviation (SD) for quantitative variables and were summarized by absolute frequencies and percentages for categorical variables. The normality of data was analyzed using the Kolmogorov-Smirnoff test. Categorical variables were compared using the chi-square test or Fisher's exact test when more than $20 \%$ of cells with an expected count of less than 5 were observed. Quantitative variables were also compared with the t-test or Mann $U$ test. A multivariate regression model was used to evaluate the factors for poor postoperative outcomes. The Kaplan-Mayer curve survival analysis used to assess the postoperative complication and free survival rate. Statistical analysis performed with SPSS version 16.0 for windows (SPSS Inc., Chicago, IL). P-values of 0.05 or less were considered statistically significant.

\section{Results}

In total, 365 patients undergoing Figulla Flex II ASD occluder insertion for ASD repair were retrospectively reviewed. The baseline characteristics are summarized in Table 1. The average age of participants was $37.19 \pm 13.30$ years at operation time and $40.06 \pm 13.21$ years at the time of assessment of patients' data. The most prevalent clinical symptom was dyspnea in $97.8 \%$, palpitation in $25.7 \%$, and chest pain in $13.4 \% .95 .1 \%$ had a single ASD defect, and the double defect found in $4.9 \%$. The mean operation time was $72.61 \pm 26.09$ minutes. Intraoperative cardiac arrhythmia occurred in 9 patients that include 4 patients with first degree AV block, 2 patients with second degree AV block (2:1), 2 patients with complete heart and one patient who needs permanent pacemaker implantation (1month after the procedure). Device embolization was observed in 4 patients that were all successfully managed by surgery. Femoral site complications were seen in 7 patients, 2 patients with retroperitoneal hematoma and 5 patients developed massive femoral hematoma that all followed and managed conservatively. Cardiac tamponade also occurred in 2 patients due to erosion (Table 2). The patients were followed for a mean time of 31.7 months (ranged 12 to 51 months). The most common postoperative complications within the follow-up time were cardiac arrhythmia (PVC in 18 patients and PSVT in 5 patients), erosion in 2 patients and clot on device in 2 patients (these patients were treated with warfarin for three months and repeated TEE after that time showed that clot was resolved.) Considering MACE (Major Adverse Cardiac Event) as the occurrence of at least one postoperative cardiac complication, the overall MACE was indicated to be $4.9 \%$. Among baseline variables (Table 4), the size of ASD and the size of the device could effectively predict the likelihood of MACE.

According to the survival analysis using the Kaplan-Mayer Curve, 1,2, and 3-year, free MACE survival rates were 99.7\%, 99.1\%, and $90.6 \%$, respectively (Figure 2). There was no procedure-related mortality in our patients.

Table I Baseline and preoperative characteristics of the study population

\begin{tabular}{ll}
\hline Age(year) & $37.19 \pm 13.30$ \\
\hline male, female & $226(61.9 \%), 139(38.1 \%)$ \\
ASD size & $18.66 \pm 5.46$ \\
Device size & $22.97 \pm 5.75$ \\
Rim type and size & \\
PS(number/size) & $240(4.32 \pm 2.44)$ \\
Al(number/size) & $210(4.36 \pm 2.92)$ \\
PI(number/size) & $250(4.94 \pm 3.92)$ \\
AS(number/size) & $135(2.01 \pm 1.25)$ \\
SVC(number/size) & $254(4.77 \pm 2.58)$ \\
IVC(number/size) & $250(5.32 \pm 3.43)$ \\
Clinical manifestation & \\
Dyspnea & $357(97.8 \%)$ \\
Palpitation & $94(25.7 \%)$ \\
Chest pain & $49(13.4 \%)$ \\
Mean RV size & $3.99 \pm 1.67$ \\
Mean shunt(Qp/Qs) & $2.20 \pm 0.80$ \\
Number of ASD defect & \\
I & $352(95.1 \%)$ \\
2 & $18(4.9 \%)$ \\
\hline & \\
\hline
\end{tabular}

PS, Posterior- Superior Rim; Al, Anterior- Inferior Rim; PI, Posterior- Inferior Rim; AS, Anterior- Superior Rim; SVC, Superior Venacava Rim; IVC, Inferior Venaava Rim 
Table 2 Peri-procedure complications of the study population

\begin{tabular}{ll}
\hline Cardiac arrhythmia & \\
\hline First degree AV block & $4(\mathrm{I} .2)$ \\
Second degree AV block(2:I) & $2(0.6)$ \\
Complete heart block & $2(0.6)$ \\
PPM implantation & $\mathrm{I}(0.3)$ \\
Device dislodgement & $4(\mathrm{I} .2)$ \\
Air embolism & $2(0.6)$ \\
Cross to open surgery & $4(\mathrm{I} .2)$ \\
Tamponade & $2(0.6)$ \\
Erosion & $2(0.6)$ \\
VTE & $\mathrm{I}(0.3)$ \\
Femoral site complications & $7(2.1)$ \\
retroperitoneal hematoma & $2(0.6)$ \\
massive femoral hematoma & $5(\mathrm{I} .5)$ \\
\hline
\end{tabular}

Table 3 Post-procedure outcome of the study population

\begin{tabular}{ll}
\hline Dyspnea & $\mathbf{I 5 ( 4 . I )}$ \\
\hline Chest pain & $16(4.4)$ \\
Palpitation & $32(8.7)$ \\
Residual shunt & $18(4.9)$ \\
Mild & $16(4.3)$ \\
Moderate & $2(0.6)$ \\
Clot on LA disk & $2(0.6)$ \\
PVC & $18(4.9)$ \\
PSVT & $5(1.4)$ \\
\hline
\end{tabular}

Table 4 Baseline and pre-procedure characteristics of the study population

\begin{tabular}{llll}
\hline Item & MACE(+) & MACE(-) & P-Value \\
\hline Patient's age, year & $38.54 \pm 14.46$ & $37.09 \pm 13.23$ & 0.606 \\
ASD size & $19.58 \pm 5.72$ & $17.74 \pm 4.69$ & 0.038 \\
Device size & $24.41 \pm 5.48$ & $22.68 \pm 5.77$ & 0.031 \\
Rim type and size & & & \\
PS(number/size) & $5.95 \pm 2.78$ & $4.19 \pm 2.31$ & 0.176 \\
Al(number/size) & $3.95 \pm 1.47$ & $4.40 \pm 2.04$ & 0.715 \\
PI(number/size) & $7.11 \pm 3.48$ & $4.76 \pm 2.76$ & 0.097 \\
AS(number/size) & $2.02 \pm 1.80$ & $2.01 \pm 1.30$ & 0.993 \\
SVC(number/size) & $6.35 \pm 3.80$ & $4.64 \pm 2.46$ & 0.190 \\
IVC(number/size) & $7.36 \pm 3.62$ & $5.15 \pm 3.31$ & 0.141 \\
Mean RV size & $4.25 \pm 1.73$ & $3.97 \pm 1.67$ & 0.429 \\
\hline
\end{tabular}

Table continue

\begin{tabular}{llll}
\hline Item & MACE(+) & MACE(-) & P-Value \\
\hline Mean shunt(Qp/Qs) & $2.07 \pm 0.43$ & $2.03 \pm 1.53$ & 0.748 \\
Number of ASD defect & & & $0.25 \mathrm{I}$ \\
I & $100 \%$ & $94.1 \%$ & \\
2 & $0.0 \%$ & $5.9 \%$ & \\
Procedure time(min) & $68.65 \pm 19.26$ & $72.82 \pm 26.5 \mathrm{I}$ & 0.575 \\
\hline
\end{tabular}

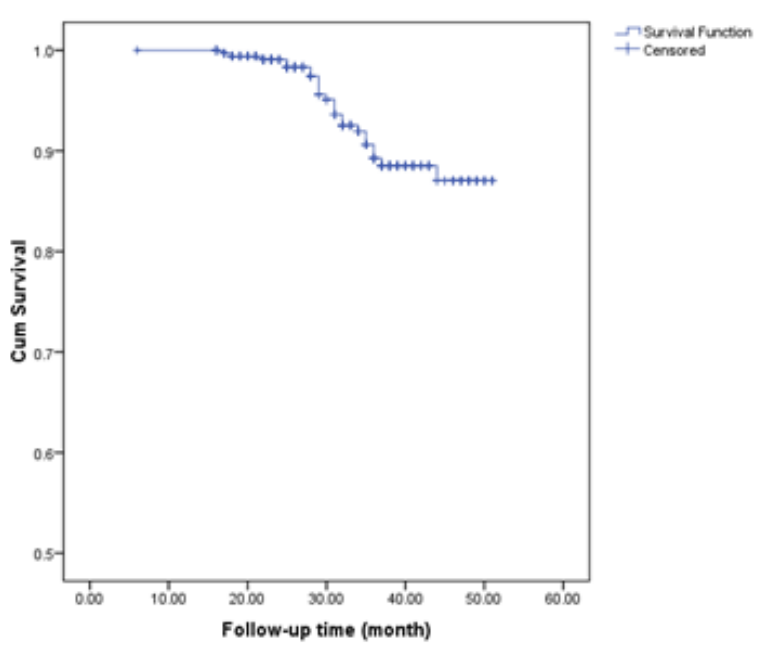

Figure I The Kaplan-Mayer free-MACE survival curve Indicates long-term survival of patients undergoing ASD closure by the Figulla Flex II ASD occluder.

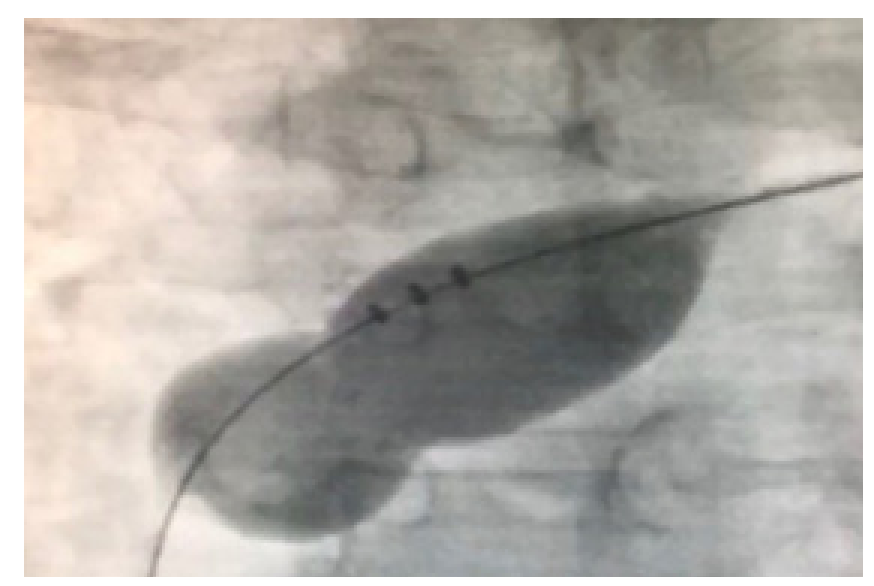

Figure 2 Sizing Balloon during the procedure of ASD closure.

\section{Discussion}

Timely and appropriately repair of CHDs, especially ASD, can lead to improvement of patients' symptoms, also, decrease the morbidity of patients by stabilizing hemodynamic status; however, such repairing techniques may lead to some cardiac adverse events, especially in the long-term period. In this regard, some patients and procedure-related parameters may predict postoperative adverse events that might be either reversible or irreversible. Indeed, identification of such factors, particularly reversible reasons, results in improving post-procedural outcomes. This study evaluates the features that have consequences for ASD repair and long-term efficacy of using Figulla Flex II ASD 
occluder device in a tertiary referral heart center to find a more unobstructed view of the values about this new device.

The study showed an appropriate and acceptable peri-procedure status as well as post-procedure outcomes within a mean follow-up time of 31.7 months. The 3 -year free MACE survival rate was found to be higher than $90 \%$ that indicates the value of the repairing procedure even in the long-term. However, some peri-procedure and postprocedure adverse events were highlighted that needs appropriate attention.

Regarding peri-procedure events, cardiac arrhythmias $(2.2 \%)$, retroperitoneal or femoral hematoma $(1.9 \%)$, and device embolization $(1.1 \%)$ occurred during or early after the procedure although all were managed successfully. Postoperatively, common complications included PVC and PSVT in $4.9 \%$ and $1.4 \%$, respectively, erosion in $0.5 \%$ and clot in $0.5 \%$ leading an overall MACE rate of $4.9 \%$. Both patients with erosion had absent anterior-superior rim that usually increases the risk of erosion. Along with some rare post-procedure complications, the value of percutaneous repair was excellent, with a considerable improvement of symptoms in almost all patients. Of course, our follow-up time was shorter than some previous cohorts that can affect the postoperative mortality as well as the survival rate. A similar study by Ozcan et al. ${ }^{13}$ in Turkey in 2018 showed no operative mortality, improving left ventricular ejection fraction, a decrease in pulmonary arterial pressure and cardiothoracic ratio. Another study by Behjati-Ardakani in Iran in $2016^{14}$ showed post-procedure recovery and improvement of the functional capacity in a mean follow-up time of 70 months and mild pulmonary hypertension in $16.2 \%$ as the most common finding; however, cardiac arrhythmias rarely occurred postoperatively. Most studies that evaluate the postoperative outcome of ASD repair considered a relatively longer follow-up that leads to notable mortality and significant postoperative complications. In a meta-analysis by Alnasser et al. ${ }^{15}$ in late 2018, reviewing nine cohort studies with a mean follow up duration 6.4 years \pm 2.7 years showed occurrence of postoperative atrial arrhythmia in $6.5 \%$, atrial fibrillation in $4.9 \%$, ASD related re-interventions in $2.3 \%$, residual shunt in $4.2 \%$, device erosion in $0.9 \%$, frame fractures in $4.2 \%$, and late migrations in $1.2 \%$. This indicates a higher risk for occurring long-term postoperative cardiac arrhythmias as compared to our report. Dramatically, in some long-term cohorts, the complication rates were far higher. Kutty et al. ${ }^{16}$ showed a mortality rate of $3 \%$ at the end of follow-up ranged from 5 to 20 years. Jeong et al. ${ }^{17}$ found a much higher mortalities of $21 \%$ after closure and $27 \%$ mortality in patients with no closure, with a mean follow-up of 6.8 years. John Sutton et al. ${ }^{18}$ revealed that adult patients with ASD closure did not have altered survival compared with a matched control group 5 to 10 years after closing. In contrast, a meager long-term survival of $40 \%$ was found in patients with ASD closure in Murphy et al. ${ }^{19}$ Overall, it seems that we achieved a proper long-term outcome of ASD device closure with Figulla Flex II ASD occluder in our center; however, the better landscape can obtain by a more extended time follow-up.

Among all baseline variables assessed, the only larger size of ASD and the size of the device could predict postoperative MACE. This fact has also been found in previous reports. According to the literature review, along with age at the time of diagnosis, the size of the defect has been reported to be an essential factor with the possibility of spontaneous closure and also its related complications. ${ }^{20}$ It has been demonstrated that for the closure of larger ASD defects, larger device size and longer procedure time may be associated with increased risk of postoperative complications, particularly supraventricular arrhythmias. ${ }^{21,22}$

\section{Conclusion}

According to our findings, ASD closure using the Figulla Flex II ASD occluder leads to acceptable long-term outcomes with no death, as well as a low MACE rate. 1, 2, and 3-year free MACE survival rates are estimated to be $99.7 \%, 99.1 \%$, and $90.6 \%$, respectively that indicating acceptable postoperative outcome following ASD closure by the Figulla Flex II ASD occluder. However, this outcome may be adversely affected by the anatomical features of defects like larger size and rims of ASD defects.

\section{Acknowledgment}

None.

\section{Conflicts of interest}

Author declares that there are no conflicts of interest towards publication of the article.

\section{Funding}

None.

\section{References}

1. Le Gloan L, Legendre A, Iserin L, et al. Pathophysiology and natural history of atrial septal defect. $J$ Thorac Dis. 2018;10(Suppl 24):S2854 S2863.

2. Celermajer DS. Atrial septal defects: even simple congenital heart diseases can be complicated. Eur Heart J. 2018;39(12):999-1001.

3. Kim HR, Jung SH, Park JJ, et al. Risk Analysis of the Long-Term Outcomes of the Surgical Closureof Secundum Atrial Septal Defects. Korean J Thorac Cardiovasc Surg. 2017;50(2):78-85.

4. Liava'a M, Kalfa D. Surgical closure of atrial septal defects. J Thorac Dis. 2018;10(Suppl 24):S2931-S2939.

5. Cowley CG, Lloyd TR, Bove EL, et al. Comparison of results of closure of secundum atrial septal defect by surgery versus Amplatzer septal occluder. Am J Cardiol. 2001;88(5):589-591.

6. Du ZD, Hijazi ZM, Kleinman CS, et al. Comparison between transcatheter and surgical closure of secundum atrial septal defect in children and adults: results of a multicenter nonrandomized trial. $J$ Am Coll Cardiol. 2002;39(11):1836-1844.

7. Brown KL, Ridout D, Pagel C, et al. Incidence and risk factors for important early morbidities associated with pediatric cardiac surgery in a UK population. J Thorac Cardiovasc Surg. 2019;158(4):1185-1196.e7.

8. Jung SY, Choi JY. Transcatheter closure of atrial septal defect: principles and availabledevices. $J$ Thorac Dis. 2018;10(Suppl 24):S2909-S2922.

9. Podnar T, Martanovic P, Gavora P, et al. Morphological variations of secundum-type atrial septal defects: feasibility for percutaneous closure using Amplatzer septal occluders. Catheter Cardiovasc Interv. 2001;53(3):386-391.

10. Haas NA, Soetemann DB, Ates I, et al. Closure of Secundum Atrial Septa Defects by Using the Occlutech Occluder Devices in More Than 1300 Patients: The IRFACODE Project: A Retrospective Case Series. Catheter Cardiovasc Interv. 2016;88(4):571-581. 
11. Roymanee S, Promphan W, Tonklang N, et al. Comparison of the Occlutech (R) Figulla (R) septal occluder and Amplatzer (R) septal occluder for atrial septal defect device closure. Pediatr Cardiol. 2015;36(5):935-941.

12. Godart F, Houeijeh A, Recher M, et al. Transcatheter closure of atrial septal defect with the Figulla ((R)) ASD Occluder: a comparative study with the Amplatzer((R)) Septal Occluder. Arch Cardiovasc Dis. 2015;108(1):57-63.

13. Ozcan S, Yener AU, Ozkan MT. Atrial septal defect repair; our early and mid-phase results. Pak J Med Sci. 2014;30(2):322-325.

14. Behjati-Ardakani M, Golshan M, Akhavan-Karbasi S, et al. The Clinica Course of Patients with Atrial Septal Defects. Iran J Pediatr. 2016;26(4): e4649.

15. Alnasser S, Lee D, Austin PC, et al. Long term outcomes among adults post transcatheter atrial septal defect closure: Systematic review and meta-analysis. Int J Cardiol. 2018;270:126-132.

16. Kutty S, Hazeem AA, Brown K, et al. Long-term (5-to 20-year) outcomes after transcatheter or surgical treatment of hemodynamically significant isolated secundum atrial septal defect. Am J Cardiol. 2012;109(9):13481352 .
17. Jeong IS, Ahn BH, Kim SJ, et al. Mid-to long-term results of surgical treatment of asd in patients over 60years old. Korean J Thorac Cardiovasc Surg. 2011;44(2):137-141.

18. John Sutton MG, Tajik AJ, McGoon DC. Atrial septal defect in patients ages 60 years or older: operative results and long-term postoperative follow-up. Circulation. 1981;64(2):402-409.

19. Murphy JG, Gersh BJ, McGoon MD, et al. Long-term outcome after surgical repair of isolated atrial septal defect. Follow-up at 27 to 32 years. N Engl J Med. 1990;323(24):1645-1650.

20. Mahoney LT, Truesdell SC, Krzmarzick TR, et al. Atrial septal defects that present in infancy. Am J Dis Child. 1986;140(11):1115-1118.

21. Komar M, Przewłocki T, Olszowska M, et al. Conduction abnormality and arrhythmia after transcatheter closure of atrial septal defect. Circ J. 2014;78(10):2415-2421.

22. Fraisse A, Latchman M, Sharma SR, et al. Atrial septal defect closure: indications and contra-indications. J Thorac Dis. 2018;10(Suppl 24):S2874-S2881. 